\title{
BERKELEY SOB UMA ÓTICA CONTEMPORÂNEA
}

\section{BERKELEY UNDER A CONTEMPORARY VIEW}

\author{
Matheus de Sousa Paula Sarmento ${ }^{I}$ \\ (math.sarmento@gmail.com)
}

Wellington Wagner Ferreira Sarmento ${ }^{2}$

(wwagner@virtual.ufc.br)

\begin{abstract}
RESUMO
Perante os avanços da tecnologia e de nosso próprio conhecimento científico, a ideia sobre a existência da matéria é dada como certa pelas Ciências. Dentro desse paradigma, as teses de George Berkeley sobre a não existência da matéria - nomeadas de Imaterialismo - soam, no mínimo, como absurdas. Faremos, portanto, uma viagem breve em seus conceitos e teorias, incluindo suas contribuições para epistemologia, buscando esclarecer se realmente sua forma de ver a realidade das coisas difere muito do pensamento científico contemporâneo atual. Nesse eixo, tentaremos estabelecer elos críticos entre o que apresentava o pensamento berkeleyriano com o que vivenciamos no hoje, sobretudo, com o advento crescente da revolução tecnológica.
\end{abstract}

Palavras-chave: Imaterialismo. Representação. Ideia. Deus.

\begin{abstract}
Given the advances of technology and our own scientific knowledge, the idea about the existence of matter is given as certain by the Sciences. Within this paradigm, George Berkeley's theses on the nonexistence of matter - called 'Immaterialism' - sound as absurd. We will therefore make a brief trip in his concepts and theories, including his contributions to epistemology, seeking to clarify if his form of seeing the reality of things really differs much from current contemporary scientific thinking. On this axis, we will try to establish critical links between what Berkeley's thought presented with what we experience today, especially with the increasing advent of the technological revolution.
\end{abstract}

Keywords: Immaterialism. Representation. Idea. God.

\section{INTRODUÇÃO}

\footnotetext{
${ }^{1}$ Graduando em Filosofia pela Universidade Estadual do Ceará (UECE)

CV Lattes: http://lattes.cnpq.br/3161668048299094.

ORCID: https://orcid.org/0000-0001-6552-2430.

2 Professor Mestre da Universidade Federal do Ceará (UFC).

CV Lattes: http://lattes.cnpq.br/1015561507843037.

ORCID: https://orcid.org/0000-0002-4711-3411.
} 
Berkeley, nascido em 1685 na Irlanda, tinha um gosto pelas obras empiristas de sua época. Entretanto, tinha um laço, um tanto inesperado, com a filosofia platônica. Tal feito é constatado com sua negação da matéria, ou, como ficou conhecido mais tarde, o Imaterialismo. Platão partia do princípio que o verdadeiro conhecimento não jazia no Plano Sensorial, moradia da matéria e, sim, no Plano Inteligível - um mundo de ideias, formas abstratas que carregam, em si, uma única verdade. No entanto, negar a matéria seria, em última instância, negar a si mesmo.

Aristóteles que disse: a filosofia nasce de um espanto, em sua Metafísica (SIQUEIRA,2016).

Usaremos como base uma definição simples, de senso comum, de matéria. Matéria é, por si, um agregado de partículas que possui massa e, portanto, ocupa espaço. Pelo menos, é assim que aprendemos nas escolas.

Paremos um pouco, reflitamos sobre tudo que se sabe sobre a matéria e sua natureza. Caso não sejamos um cientista, é provável que nunca tenhamos visto a matéria em si, mas apenas o fenômeno dela. Ou seja, como ela aparenta ser (Plano Sensorial) e não como ela realmente é (noumeno, Plano Inteligível) (MOSER, MULDER e TROUT, 2004), portanto, é possível que você tenha uma crença, ao invés, de conhecimento pleno deste fato. Uma crença é algo social, sobrevivendo mais facilmente quando compartilhado por um grupo ou sociedade. Portanto, pode ser falsa por duas razões:

1. Um grupo é formado por pessoas. Seres humanos podem errar ao longo de suas vidas. Pessoas são humanas. Logo, pessoas podem errar.

2. Dependendo do contexto utilizado, a sua crença pode trilhar um caminho contrário à verdade. Atualmente, no tempo e espaço que estamos, a Terra é redonda. Nada impede, por sua vez, desse grupo crer que ela não seja assim.

Verdade, em si, é uma problemática que tem deixado os filósofos inquietos por eras. Nesse momento, usaremos o conceito de verdade contextual pela ótica de Wittgenstein. A verdade muda em função do tempo e espaço em que nos encontramos (VENÂNCIO,2017). Por exemplo, nos jogos de linguagem, onde a palavra manga pode diferir dependendo de seu contexto, ou qualquer sentença, em que é colocada. Pode ser manga da camisa ou pode ser manga fruta. Notamos que a mudança de contexto reflete na mudança de significado.

O problema tem uma aparência sutil, mas está lá. Quando usamos o contexto em função da verdade, estamos à mercê de um relativismo. Ou seja, abre- 
se mão da certeza por uma ideia de que a verdade depende de terceiros. Nesse contexto de Wittgenstein, uma dúvida surge, a existência da própria matéria.

Uma crença terá uma vida por si só, porém, muitas vezes, uma justificativa é necessária. Como base para sua Doxa - opinião, como diziam os gregos - podemos fazer o mesmo caminho que a filosofia grega e logo esbarramos em sua predileção pelo sentido da visão. Tal como Berkeley, eles sabiam da importância desse sentido, pois era através dele que se acreditava testemunhar a beleza, o mais próximo do Belo, em si, que chegaremos. O filósofo irlandês, entretanto, terá algo a acrescentar à linha de raciocínio dos gregos.

Platão e Berkeley, apesar de separados por séculos, mantinham um leve elo que pode ter sido ignorado: a dúvida sobre a matéria. Nesse instante, colocamos uma linha entre eles embora, certamente filósofos consagrados, eles estavam submetidos ao espírito de sua época.

A tradição Platônica admitia uma verdade única que, em essência, era uma Forma Inteligível. Por consequência, é algo que não varia em sua identidade e que não depende de causas anteriores para existir. Uma segunda, e marcante, distinção é sobre o que diz respeito ao sensorial. Berkeley (2010), como um bom empirista, não poderia aceitar a tese Platônica de que os sentidos não teriam um papel decisivo para a aquisição do saber. Aqui vemos uma diferença significativa sobre os conceitos relacionados ao plano sensorial de ambos os filósofos.

Existe, para esse filósofo Imaterialista, uma experiência originária das sensações. Algo que, efetivamente, ocorre após nosso nascimento. Nesse momento, recebemos o primeiro estímulo com o mundo. Através dos olhos percebemos as luzes e cores. O olfato e tato nos permitem conhecer sabores e texturas. O ouvido, em última instância, leva-nos aos sons (CAPPELLO, 2005).

O problema aqui torna-se para nós evidente. Não temos acesso às memórias dos nossos primeiros meses. Não recordamos, literalmente, da primeira vez que andamos ou qual foi a primeira palavra por nós pronunciada. Mas, mesmo sem essa memória de eventos, sabemos como andar e falar até esse momento. Podemos explicar, mesmo sem a ciência, a origem desse ato e como executá-lo para o outro interlocutor.

A resposta para isso, segundo Berkeley, está na repetição de estímulos. Como base, iremos usar o processo do aprendizado do andar. Inicialmente, nossas pernas doem e os pés, infantes e pequenos, tropeçam. Nós sentimos o chão com nosso tato, sem reconhecer a 
princípio suas formas e texturas. A distância, auxiliada por nossa visão, é percebida e sugerida. Porém, só é realmente vivenciada com a união do visual com o tátil (CAPPELLO, 2005).

No processo de andar e conhecer o espaço ao nosso redor, sentimos dores, nossa atenção estará, em seu máximo, no próprio ato. Entretanto, à medida que andamos e os dias se tornam anos, o andar não é mais um fardo. $\mathrm{O}$ andar é, portanto, um gesto administrado em conjunto com outras ações. Podemos, por exemplo, mexer as mãos enquanto nos movemos respectivamente, uma ação secundária e uma ação primária.

Essa lógica pode ser aplicada em nossa própria percepção do outro. Suponha-se que um jovem, nomeado de John, nunca viu o mar. Ele ficará surpreso com o mar, demora mais para se acostumar com suas formas. Muito similar, por sua vez, ao bebê e seu andar. A primeira vez que o olhar, não será como as próximas vezes. A emoção se tornará uma memória para ser resgatada, e o mar, em nossa mente, acaba por ser apenas uma representação ao invés do fato em si. Representação essa, em essência, movida por uma imaginação.

Uma representação, por definição, não é a coisa em si. Não é matéria - algo físico mas sim, a ideia sobre algo. Uma imagem. Uma ideia pode estar errada. Nosso corpo percebe a diferença de temperatura das coisas comparando sua própria temperatura com o objeto externo. Se o objeto tiver temperatura muito menor, será sentido como fria por nosso corpo, logo a pele terá a sensação áspera, cortante, como consequência direta. Desta sorte, a verdade que carregamos não pode ser sustentada, ou justificada, por algo que nos engana.

Ideias nos traem, assim como, para o platonismo, os sentidos nos guiam à confusão e discordância (ANTISERI e REALE, 2016). Resta, então, recorrer ao Argumento de Autoridade. Em outros termos, crermos que um determinado indivíduo tem maior conhecimento, status sapientiae, para resolver uma determinada questão.

Dois problemas podem ser encontrados e estudados, nesse raciocínio.

1. Autoridades são pessoas ou instituições formadas por elas. já discutimos, anteriormente, vimos que pessoas erram.

2. Uma autoridade não possui, em seu arsenal, o Valor de Verdade próprio. Apenas é capaz de, com seu status, fortificar uma tese já apresentada.

Se o conhecimento, em si, pode ser frágil, e até mesmo falso, o que garante a veracidade da matéria? 


\section{DESENVOLVIMENTO}

Nós somos, por natureza, seres sociais. Em períodos pré-históricos precisávamos caçar em grupo com o intuito de maximizar as chances de sucesso e, por consequência, aumentar nossa chance de sobrevivência. Isso, de maneira direta, garantiu nossa vaga na evolução. Essa característica moldou-se com o passar do tempo e as mudanças no espaço, no atributo oscilante que chamaremos de contexto (HARARI, MARCOANTONIO, 2015). O social, dentro dessa ótica, tornou-se um elemento mais sofisticado e complexo. Deixou-se para trás a necessidade e focou-se na ausência de algo. O desejo que se recusa a cessar.

O capitalismo, sistema de produção em vigor na maior parte do mundo, tem como intuito o acumular de riquezas e, por extensão, o acúmulo de bens. Esses bens, por definição, são físicos e, portanto, são matéria. Negaremos ir muito distante para comprovar essa afirmação. Caso olhe um shopping em uma hora de pico testemunhará cabeças jovens e grisalhas gastando seu tempo olhando as vitrines e indagando-se sobre o que devem ou não comprar. Movidos pela crença, afastando-se da razão a cada passo. A propaganda e a lógica de consumo do Capitalismo fazem com que a razão perca espaço para as crenças construídas. A felicidade, nesse espaço e tempo, para muitos é adquirir determinado objeto (BAUDRILLARD,2009).

$\mathrm{Na}$ última palavra do parágrafo anterior está uma questão interessante. Para tantos de nós, quando pensamos em um objeto associamos diretamente com algo físico. Um exemplo simples disso seria uma cadeira ou um lápis. Podemos tocá-los, sentir as suas texturas, entretanto, não podemos ir além do que ele aparenta ser. O que ele é, em si, continua a ser um mistério para os filósofos idealistas ou logicistas. Nós damos um nome, uma indicação, do que temos crença de que seja uma cadeira. Porém, nada impede que uma pessoa - que nunca teve contato com esse objeto até então - a nomeie de maneira diferente ao refletir sobre sua forma.

Berkeley teve uma aproximação com a Filosofia da Linguagem, ao nosso ver, ao ponto de dizer que as palavras, nosso vocabulário, não passam de ideias que atribuímos a elas (VENÂNCIO, 2017). Wittgenstein e sua tradição analítica, mais uma vez, são citados aqui.

Ao nos apoderamos do conceito de verdade contextual admitimos, de maneira natural, 
que determinadas pessoas ou grupos podem ter ideias diferentes sobre algo, significados distintos para uma mesma coisa. Mais especificamente, Berkeley (2010) usará como termo percepção.

Suponhamos um cenário: se nossa linguagem é feita de ideias, o que impede que um objeto que tocamos com nossos dedos e vemos não passe de uma ideia, uma interpretação? Aquela roupa que almejamos comprar por grande quantia em dinheiro, é desejada por ser bem-feita ou somente pelo fato de ser mais cara? Ou ser de uma marca de renome? Uma marca é uma ideia que parte de uma sociedade e carrega um juízo, um valor, da qual ela deposita nesse produto. Tire o símbolo e verá essa mesma roupa mais barata no mercado.

O mesmo vale para nossos relacionamentos. No princípio, nós temos paixão e ela move as engrenagens para irmos adiante. Em muitos casos, há o amor em estágio platônico, onde ocorre a adoração ao outro, seus defeitos são camuflados e passam despercebidos por uma razão embriagada. Para os apaixonados o objeto da paixão é uma ideia que temos sobre a pessoa ao invés do que ela é realmente.

Entretanto, na visão de Berkeley, há apenas uma relação de importância que tanto está além da negação quanto da simples ignorância: Deus e o Outro. O Outro, para Berkeley, é a mente contida na consciência divina, a pessoa. É preciso entender o que levou este filósofo a chegar a essa conclusão. Devemos ter em mente que nossas experiências, nossas crenças individuais, influenciam nossas obras, tudo aquilo que fazemos pode ter um toque delas. Embora, isso possa ser discutido - assim como se essa influência se dá no âmbito consciente ou inconsciente - não entrarei no mérito dessa questão.

Deus é uma palavra muito usada e de maneiras distintas. Serve tanto para justificar a violência em si - vide as cruzadas - quanto para invocar ideias de amor e paz. Uma vez que seu uso é diverso, não seria tão espantoso aceitar a ideia que seu significado também compartilhe da mesma caraterística. Ainda mais se considerarmos o campo vasto da linguagem. Um exemplo é a concepção inicial de deus judaico-cristã. Era algo subjetivo, era como se fosse um Deus pessoal. Enquanto, na atualidade, essa premissa está fraca e perdendo seu lugar para um deus mais coletivo.

Deus, na ótica de Berkeley, é essencialmente bom (MENDES, 2007). Ele, em suas próprias convicções, nunca haveria de nos enganar. Muito similar a um ente querido, pai ou filho, no qual escolhemos depositar um certo grau de credibilidade e, por extensão, confiança. Entretanto, é no Ser divino que esses atributos ganham, ou melhor, alcançam o grau máximo. Desde o instante que tomo ciência desse Ser, o percebo como único, 
infinito e que não está amarrado com o fluxo do tempo. Em uma tradição Platônica, isso assumiria o nome de uma Forma Inteligível.

Voltaremos um pouco atrás, ousaremos analisar o próprio tempo em si. Nós, no papel de humanos, estaríamos sujeitos a sua passagem. O fato de estarmos em um ciclo de nascimento, vida e morte é por si só e para muitos, uma prova suficiente tanto de sua ação quanto de sua existência. Porém, o cenário há de mudar quando colocamos sua natureza para ser vista de um ângulo mais crítico, afastado e não derivado de um senso comum.

Comum se tornou falar que o tempo é linear. Em outros termos, que existe em uma continuidade entre passado, presente e futuro. Por natureza, não podemos mudar o que ocorreu, mas, apenas, podemos focar nossas forças no momento com intuito de atingir um futuro hipotético e mais desejável. Entretanto, nada impede alguém de afirmar que o tempo é constituído só do agora. Essas duas premissas podem ser ambas verdadeiras ou falsas, não sendo necessariamente contraditórias.

No ponto de vista teológico, essa lógica de sucessão de eventos é tanto enfrentada quanto apoiada, e usada pela comunidade da época de Berkeley. A causalidade entra na boca de muitos homens cultos, alguns até levantam a ideia de Causa Primária - nesse caso, Deus como o motor dos eventos e da própria existência.

Alterando-se um pouco o rumo de nossa argumentação, buscaremos entender o que é ter uma relação com Deus e vice-versa. Isto é importante para entendermos Berkeley. O ser humano é um ser social, sites como Facebook e Instagram provam isso. A interação nestas redes sociais se reduz a uma série de fotos, vídeos, com o intuito de possibilitar que o indivíduo tenha seus "quinze minutos de fama". Temos um forte senso de buscar nossa identidade, e quando isso não é achado a saída adotada é criar uma ardilosa representação de nós mesmos. Uma que seja confortável para seu eu.

Façamos um exercício de imaginação. Viajaremos para alguns séculos no passado. Imaginemo-nos lendo as reflexões da obra: A República de Platão. É nela que vemos o que seria, talvez, o exemplo mais usado no ensino médio com um intuito simples e claro: servir como porta de entrada para a filosofia. A alegoria da caverna está na boca de muitos e entendido na mente de poucos. Iremos, portanto, usar a mesma alegoria.

Haviam três pessoas em uma caverna, acorrentados de tal maneira que só uma parede de pedras era o suficiente para resumir sua realidade. As sombras que lá passavam, vez ou outra, acabavam por ser sua única fonte de diversão, um entretenimento fugaz. Talvez, depois de um tempo, eles começaram a perder sua noção de identidade, 
mas nada disso importava. As silhuetas, em última instância, eram aquilo que seus olhos tinham certeza que era a totalidade das coisas.

Suponha então que uma dessas pessoas escape de suas correntes. Andar, muito possivelmente, seria uma dor notável. Entretanto, isso não o impede de explorar a caverna e, diga-se de passagem, sua única zona de conforto. Seria mais fácil tomar a pílula azul e continuar na "Matrix" ${ }^{3 "}$ de uma forma que isso nunca teria acontecido. Contra seus instintos ele foi em direção aos poucos raios de luz que vinham de fora. O sol o cegava, porém, o que veria a seguir valeria o preço: o mundo.

Uma das grandes questões de Berkeley (2010), herdada de Locke e sua tradição empirista, a qual lia com tanto afinco em sua juventude, era o que aconteceria quando deixamos de perceber o mundo ao, por exemplo, fechar os olhos. Será que o real apenas desapareceria? Essa indagação deixa uma marca fascinante e há de caber nos moldes da alegoria que nos debruçamos acima. O homem, no fim, goza de sua liberdade e isso é um fato. Mas, pouco sabemos das dúvidas de sua cabeça. Será que aquilo diante dos seus olhos sempre existiu? Se partimos da premissa que aquilo que percebemos é o que determina o valor de existência das coisas, o mundo ainda continuará a existir caso escolhesse voltar para onde veio?

Usando a alegoria da caverna, em um registro puramente hipotético, digamos que a primeira coisa que uma pessoa ao sair da caverna veja seja um rio. Pode vê-lo e sentir seu cheiro. Ele anda em sua direção com entusiasmo e a caverna desaparece de seu campo de visão. Para os prisioneiros restantes nela, cativos, ela continuaria sendo percebida e, por consequência direta, existindo. Entretanto, para o homem livre, o local não estaria sob a jurisdição de seus sentidos, sua percepção. Logo, dentro desse raciocínio, sairia de seu mundo.

Mundo é um termo muito usual. E, como já discutimos, palavras não passam de ideias. Sobre a guarda desse pensamento iremos cunhar, com inspiração de Berkeley, uma definição própria. O mundo seria, portanto, o que percebemos naquele tempo e espaço. Desse ponto em diante tomamos uma liberdade sobre esse autor uma vez que, em alguns escritos, questiona Newton e põe essas propriedades em xeque. Colocaremos, por agora, as duas na esfera da física, de uma forma um tanto leiga, para fins de compreensão didática.

Se usarmos como exemplo o exercício mental de uma casa, após fechar a porta,

\footnotetext{
${ }^{3}$ Filme de ficção científica lançado em 1999 e que trata de uma realidade construída no subconsciente compartilhado de vários humanos.
} 
deixamos de ter contato com o exterior em si e somos, sem alternativa, postos à mercê de nossa memória. Em essência, a memória é uma representação com furos preenchidos por nossa imaginação. Imperfeita. Logo, a coisa em si deixaria de existir em nossa mente, restando apenas sua ideia. Um evento similar atinge o nosso homem livre na alegoria: pode ter escapado de sua caverna, porém, uma representação dela ainda permanece. Uma discussão pode ser aberta diante dos dois homens que permanecem acorrentados. Será que eles poderiam ter uma ideia própria do rio? A resposta que daremos passa longe de ser definitiva, caindo no mérito de uma mera suposição: Eles teriam que ter a experiência originária do rio para, então, abrir-se margem para uma representação.

Locke acabou por ser um dos pilares do empirismo inglês e, como tal, suas obras tiveram impacto em boa parte da comunidade culta da época. Sua tese sobre o ser humano vir ao mundo como uma tábula rasa a ser preenchida pela experiência, pela interação que temos com o meio, foi de encontro ao princípio de Ideias Inatas proposto por Descartes - conceito de que, ao nascermos, dividimos um conjunto de ideias, uma herança da semelhança que compartilhamos com o Criador - e isso o rendeu elogios e críticas (PIMENTA, 2007).

Como um derivado dessa premissa, Locke se dedica mais sobre a nossa interação com os objetos. Em sua visão, os objetos compartilham, entre si, qualidades de cunho primário e secundário.-Aquilo que é inato delas - forma, número - e o que percebemos pela experiência, por via subjetiva - como cores, odores - existiam, separadamente, em cada consciência individual.

Pontuamos aqui uma observação, Berkeley (MENDES, 2007) expõe que as coisas aqui apontadas como ideias - apesar de interagirem com os sentidos através do que podemos chamar de sensações, tem todas as suas propriedades - ou qualidades, como consta no verbete lockeano - digeridas e processadas no ângulo da mente. Portanto, são traduzidas de maneira subjetiva. Sendo um mecanismo interno o responsável por isso, podemos colocar em tese que tudo que é sentido, vivido, não escapa das amarras da mente. Mas, nesse ponto, seria da nossa própria ou de um outro ser?

Berkeley era um bispo. Começando como diácono da igreja Anglicana, bastante culto em sua era, sentiu a ausência de Deus nas teorias recentes empiristas. O crescimento de ateus da época, além das teorias produzidas por eles, possivelmente o motivou e serviu como motor de seus escritos. Em sua concepção, Deus seria a mente primordial e nós, como seres inferiores, funcionamos como produtos dela. 
Recuperamos, então, o conceito da relação mais importante: Deus e o Outro. O Outro, portanto, é a nossa mente em relação constante com o próprio divino. Dentro desse contexto, podemos supor, não fora das sutilezas de uma interpretação, que poderia haver um embate entre as duas potências - entre o divino e o humano - para decidir qual consciência iria sobrepor a outra.

O pensamento contém a possibilidade da situação que é pensada. "O que é pensável é também possível", essa é a célebre frase de Wittgenstein (2010). O Outro poderia pensar uma realidade e essa, por sua vez, ser uma alternativa. Entretanto, Deus vai além das amarras da possibilidade, ele é, em essência, a vontade e o ato. O que deixaria, para nós, uma única saída: depositar nossa confiança Nele. Algo que, para Berkeley, seria natural.

Estaríamos, nessa altura, na consciência de Deus e o nosso mundo não passaria de nossa representação do que seriam suas mensagens, trazidas pelas sensações. $\mathrm{O}$ conhecimento, então, se resumiria ao que percebemos. Nós só existimos enquanto há um outro para nos perceber. A existência é como uma relação desigual, onde Um existe em função do Outro - leia-se Deus nesse momento - mas o Outro não necessita deste Um.

Tirando o caráter divino, podemos enxergar isso nos relacionamentos a nossa volta. Em qualquer fase da vida, é possível encontrarmos pessoas que, sem elas, não existiríamos. Entretanto, para elas, isso não é mútuo. Nós sabemos o que é necessário. Se para saber algo precisamos, em primeira mão, perceber, então, para uma criança de poucos meses, provavelmente não exista uma noção de economia pois, em sua visão, apenas seus pais são necessários. Porquanto, para grandes economistas, esse conhecimento é fundamental.

Trabalharemos um pouco na relação entre os termos necessário e conhecimento. Imaginamos Deus e um Outro nascido em sua consciência. É como uma linha telefônica da qual só um lado pode falar. Quem está ouvindo fica restrito a apenas interpretar o que é dito. Agora, usando dessa metáfora, sobra-nos saber o conteúdo que é exclamado. As opções são infinitas, mas nos limitaremos a dizer que, de forma simplificada, é assim que o conhecimento é transferido de um ponto - Deus - para outro - mente contida no divino.

O Outro não pode escolher o que lhe é transferido, a mensagem e o conhecimento embutido nela, enquanto, para Deus em Berkeley, só é feito aquilo que pode ser percebido, necessário. Afinal, o Senhor não faria esforço em criar algo que não fosse para ter um significado. Logo, se Ele escolheu passar uma mensagem para um produto de sua consciência - nós - essa mensagem é movida por algo que é preciso. 
O próprio fato de não podermos escolher a natureza da mensagem que nos é imposta é perigoso para um sistema baseado no Livre Arbítrio. Entretanto, pode-se levantar o ponto de que usufruímos de nossa liberdade no ato seguinte, a representação. Partindo da premissa de que o que percebemos é o que sabemos, essa decisão seria tomada por necessidade ou liberdade?

Encaminhando-nos para um final, colocaremos na mesa a seguinte problemática: o que acontece quando deixamos de perceber algo? Essa foi uma indagação pincelada muitas vezes durante esse texto e, ainda sim, não teve a atenção merecida. Podemos tratar isso com duas visões: uma delas de raiz mais teológica fazendo menção às crenças de Berkeley ou de uma linha menos religiosa, de ângulo filosófico menos ortodoxo.

Usaremos, para tal, o desfecho da alegoria da caverna antes posta. O homem livre se aproxima do rio e a caverna está distante de seus olhos. Na primeira solução, a propriedade de Onipresença de Deus é testada e permite, por sua vez, que a caverna exista longe da percepção do homem, pois, pela definição de Onipresença, há de se colocar que Deus está olhando tudo o tempo inteiro. Por consequência, se Ele parar de nos observar logo deixaremos de existir.

Numa segunda vertente, admitamos "ser é perceber" como uma premissa válida. O próprio fato de conseguirmos fazer uma representação de algo a partir de um primeiro contato, misturado com nossas características subjetivas - imaginação e memória - indicaria que é em nossa em mente, contida em uma consciência superior, que residiria a possibilidade de algo registrado poder ser percebido novamente. Isso, caso aceito, permitiria um olhar distinto à máxima tradicional de Berkeley: ser é perceber e poder ser percebido.

É fundamental ilustramos aqui o que difere uma mente de um objeto. Muitas vezes dizemos que o objeto, na tradição Imaterialista, é uma ideia. Enquanto isso pode bastar em relação a mente, o objeto para Deus se revela mais complexo. Como o divino tem, em sua propriedade ímpar, a onipresença, o objeto, tendo-o como referência, sempre estará lá. A mente, porém, não tem essa certeza. Muitas vezes traduzido como espírito, a mente é um ser que age e reage, tendo a mutabilidade como uma de suas principais características. O objeto, mesmo estando sempre lá, é inerte em sua mais profunda natureza. Deus pode conviver com um número incontável de espíritos, entretanto, um espírito raramente percebe outro, dandolhe uma visão de que somente ele existe com Deus. 


\section{CONSIDERAÇÕES FINAIS}

Em nosso breve percurso, contemplamos as noções básicas do pensamento de Berkeley, tais como o conhecimento, chegado em nós tanto pelo externo (sentidos) quanto por meios internos, vistos como operações da mente ou, para ser direto, o próprio pensamento. Introduzimos a relação entre Deus e o Outro e sua importância para o saber como um todo. Também, como um último mérito, estabelecemos uma rápida associação entre o Imaterialismo e a linguagem em Wittgenstein, o que permitiu o elo entre o pensamento berkeleyriano e a filosofia contemporânea.

Sobre esse último ponto, uma observação é necessária: quando assumimos a relação da palavra - um conjunto de letras, símbolos com um significado - com a ideia, agindo no papel representativo, estamos, em última instância, representando uma representação primeira (ideia) com uma representação segunda: a própria palavra. Assim, a ideia não é necessariamente a palavra dita. Pode haver, então, um problema de correspondência.

Dando foco ao âmbito do conhecimento, visto aqui como fruto da relação de Deus e o Outro, quanto mais aprofundamos essa dinâmica, mais podemos visualizar uma possível influência da Trindade cristã: Pai, Filho e Espírito Santo. O Filho tomaria a posição do Outro, o Pai seria, por sua vez, a representação do conhecimento quando chega em nossos sentidos. Sobrando, assim, para o Espírito Santo o papel de ser o conhecimento e intermediário.

Um segundo exemplo que toma a figura da Trindade é a questão do Amor em Agostinho (1995). Um autor que, curiosamente, influenciou Descartes e logo, em última instância, supomos crucial para as obras de Berkeley. O Amor, enquanto posto no livro A Trindade, é o terceiro ser, necessário para que o amado e amante sequer possam existir. Esse terceiro ser toma forma de Deus que é, por definição, o amor dito como absoluto.

Se considerarmos tudo que foi estabelecido, podemos nos dar ao luxo de transportarmos essa dinâmica de saber berkeleyriano para lentes mais atuais. Estamos sendo uma parte viva do fenômeno recente nomeado de redes sociais, como Facebook e Twitter. Quando nos pomos como um usuário do meio, tendemos a seguir aqueles que reforçam apenas nossa própria percepção de mundo. Colocamos, assim, uma venda em nossos olhos e só vemos um aglomerado de indivíduos. Mídias tornam-se nossa única fonte de informação em paralelo com Deus, sendo a fonte única de conhecimento para o Outro.

A representação de Deus concebida por Berkeley é aqui defendida como um Ser onde a bondade e perfeição fazem parte da sua essência. Porquanto, segui- 
lo seria um ato imaculado. O mesmo não pode ser dito quando colocamos qualquer mídia ou indivíduo nessa posição. Ao optarmos por segui-los estamos, de maneira direta, confiando em uma fonte que, por natureza, tem uma possibilidade de estar errada. O Outro desse sistema torna-se aqui o usuário, aquele que recebe a informação tal como o Outro recebia as mensagens de Deus. Ele tem o direito de interpretar - representar para si - o que leu ou ouviu. Essa faceta do processo talvez seja a mais importante, onde mora a subjetividade de cada um. A percepção que temos de um objeto é, em última instância, um fruto do que podemos imaginar casado com aquilo que fora vivido.

Todavia, o presente sofre com a relação constante entre a informação ${ }^{4}$ e a bolha social. O último, embora normalmente entendido como algo próprio dessa era, pode ser visto como uma potencialização - através da tecnologia - de uma necessidade que remete a natureza: sentir nos aceitos por um grupo e, por sermos seres sociais, podermos sacrificar nossa percepção individual - mais subjetiva - de algo por uma de caráter mais coletivo.

Ao invés de ocorrer uma percepção única e lapidada sobre algo, os usuários vestem moldes de uma opinião já gritada por muitos. Ou seja, eles não pensam sobre. Note que, no sistema de Berkeley, para haver o conhecimento sobre algo é necessário, de início, ter suas impressões próprias sobre a mensagem transmitida por Deus. Caso isso não ocorra, a mente não reage, em uma derradeira análise, abrindo mão da propriedade que a difere de ser mais um entre tantos objetos.

Deus, em essência, é bom e perfeito para a fé que repousa em Berkeley. Por consequência, todo conhecimento obtido através Dele não pode ser pervertido. Entretanto, quando um meio ou pessoa toma a função Dele como fonte nessa equação, o mesmo não pode ser dito. Pessoas tendem a possuir uma moralidade de tom mais acinzentado e, devido a isso, discussões de ódio são cada vez mais rotineiros na Internet.

Discurso de ódio será tratado aqui de uma maneira deveras simplificada e, como consequência, um tanto genérica. Cai em seu conceito toda manifestação que visa inferiorizar o outro a título de qualquer característica mental, física ou social que possua. Por vezes, criando uma relação de poder entre aquele que faz o discurso e seu alvo.

Lidamos com o mundo a partir de nossas experiências, de nossas percepções, acostumados a nos colocar no centro de tudo. Tal sintoma é observado na adolescência, quando estamos mais propensos a acreditar que tudo acontece em função do Eu. Em outras

\footnotetext{
${ }^{4}$ Aqui vemos a informação definida como um conjunto de dados. Enquanto, o conhecimento tende a ter uma maior complexidade (MOSER, MULDER e TROUT, 2004)
} 
termos, esse pensamento, de cunho narcisista por natureza, dificulta o desenvolvimento da empatia - capacidade de se colocar no lugar do outro. Como sequela direta, tendemos a nos manter cegos, negar até a última instância, a presença do mal em nossos atos.

Quando se é um usuário e, exemplificando, recebe-se diariamente a mesma notícia de sua bolha social - nesse caso, um discurso de ódio - torna-se automático você a compartilhar em sua timeline para os demais. O teor de sua notícia será irrelevante para consigo. Pois, você não a interpreta, apenas a recebe e a transmite. Se, porventura, for preconceituosa você não irá perceber e, portanto, ela não será má diante de seus olhos. O mal, em si, poderia apenas começar a pulsar quando é concebido pela mente. Ele é extremo e, como efeito, não é inato no que diz respeito à consciência.

Ainda se empoderando dessa veia que traz o pensamento de um filósofo do século XVIII para uma ótica mais compatível com nossa realidade, seguimos com os dois finais exemplos de como o Imaterialismo deixou um legado ativo para a ciência.

$\mathrm{Na}$ física, não podemos notar a velocidade e a posição de uma partícula ao mesmo tempo.

Se o saber, e existência de um outro, como premissa, se resume ao que empiricamente percebemos, no instante que determinamos a velocidade da partícula, a sua posição não existe para nós. Uma maneira de solucionar isso é admitir a chance de existir um ser onipresente que, ao perceber todos ao mesmo tempo, permitiria que a posição fosse percebida e, assim, continuasse existindo fora de nosso alcance (PIZA, 2003).

Por fim, podemos nos ater sobre uma problemática colocada em segundo plano no ângulo do desenvolvimento dessas reflexões. A título de curiosidade, a Teoria da Relatividade de Albert Einstein foi influenciada, até certo grau, pela concepção de Berkeley de tempo e espaço. Essa, por sua vez, colocou Newton na linha de fogo. De cunho mais didático, iremos levantar os dois raciocínios.

Newton irá posicionar uma premissa única para explicar seu conceito de tempo: Princípio de Tempo Absoluto (SOUZA, 2014). Ele irá se debruçar sobre uma ideia de tempo que age independente dos objetos. É, por si, uma ótica única que pode ser percebida no viés matemático. Esse tempo seria dito como o mais puro, verdadeiro, entre os dois. O próprio fluir abstrato do universo.

A ideia de um tempo como absoluto soava estranho para Berkeley e essa estranheza inicial o motivou a colocar o tempo como algo que necessita do objeto para existir. O tempo existe à medida que o objeto, no caso sendo um sujeito, o perceberá. O 
cessar de sua existência, portanto, se dá quando o mesmo não pode mais percebido pelo pensamento (percepção interna) e os sentidos (percepção externa). A Teoria da Relatividade (Restrita) (EINSTEIN, 1999) diz que o tempo passa mais lento diante de objetos cada vez mais rápidos. O famoso exemplo do homem que foi ao espaço cabe aqui: para um astronauta, um ano no espaço será vinte anos para seus companheiros em terra - no caso, a velocidade da nave usada teria que ser quase a da velocidade da luz. O tempo, em conclusão, se mostra relativo e não independente da percepção de cada um. Essa tese bebeu dos ensaios berkeleyrianos. 


\section{REFERÊNCIAS BIBLIOGRÁFICAS}

ANTISERI, Dario; REALE, Giovani. Filosofia: Antiguidade e Idade Média. Paulus Editora; Edição: 1ª ISBN-13: 978-8534941914, 2016.

BERKELEY, George. Obras Filosóficas. São Paulo: UNESP, 2010.

BAUDRILlARD, Jean. A Sociedade de Consumo. Edições 70; Edição: 3ª ISBN-13: 978-9724415215, 2 de março de 2009

CAPPELLO, Maria Adriana Camargo. A crítica à abstração e à representação no imaterialismo de Berkeley. Curitiba: doispontos, vol. 1, n. 2, p.57-73, jan/jun, 2005.

EINSTEIN, A. A Teoria da Relatividade Especial e Geral. Rio de Janeiro: Contraponto, 1999.

HARARI, Yuval N.; MARCOANTONIO, Janaína. Sapiens: Uma breve história da humanidade. L\&PM Editores; Edição: 1,2015.

MENDES, F. C. R. O Imaterialismo de George Berkeley: O Realismo no "esse é percipi". Porto Alegre: UFRGS, 2007. 163 f. Dissertação - Programa de Pós-Graduação em Filosofia, Instituto de Filosofia e Ciências Humanas, Universidade Federal do Rio Grande do Sul, Porto Alegre, 2007.

MOSER, P. K.; MULDER, D. H.; TROUT, J. D. A Teoria do Conhecimento: Uma Introdução Temática. São Paulo: Martins Fontes, 2004.

PIMENTA, Pedro. P. G. John Locke: Origem e Formação das Ideias. Mente, Cérebro e Filosofia. São Paulo: 23-25, 2007

PIZA, Antônio F. R. de T. Schrodinger e Heisenberg: A Física Além do Senso Comum. São Paulo: Ed. Odysseus, 2003.

PLATÃO. A República. Rio de Janeiro: Ed. Nova Fronteira, 2014

SANTO AGOSTINHO. Patrística - Trindade. São Paulo: Ed. Paulus, vol. 7, 1995.

SIQUEIRA, Ana C. de A. O significado de filosofia na metafísica de Aristóteles e sua influência no pensamento de Heidegger. Kínesis, Vol. 22 VIII, ${ }^{\circ}$ 18, p.18-30, Dezembro 2016.

SOUZA, L. E. R. Sobre o idealismo em Kant e Berkeley. Studia Kantiana, Rio de Janeiro, v. 12, n. 16, 2014, p. 52-64.

VENÂNCIO, Rafael D. O. O jogo de linguagem: Wittgenstein, Teoria dos Jogos e Comunicação Social. Amazon Servicos de Varejo do Brasil Ltda, 2017. 
WITTGENSTEIN, L. Tractatus Logico-Philosophicus. São Paulo: Ed. da Universidade de São Paulo, 2010. 